BMJ Open Sport \& Exercise Medicine

\title{
Prevalence and correlates of physical activity in a sample of UK adults observing social distancing during the COVID-19 pandemic
}

Lee Smith (1) , ${ }^{1}$ Louis Jacob, ${ }^{2}$ Laurie Butler, ${ }^{3}$ Felipe Schuch, ${ }^{4}$ Yvonne Barnett, ${ }^{5}$ Igor Grabovac, ${ }^{6}$ Nicola Veronese, ${ }^{7}$ Cristina Caperchione, ${ }^{8}$ Guillermo F Lopez-Sanchez (D) , 9 Jacob Meyer, ${ }^{10}$ Mohammad Abufaraj, ${ }^{11}$ Anita Yakkundi, ${ }^{12}$ Nicola Armstrong, ${ }^{13}$ Mark A Tully ${ }^{14}$

\section{ABSTRACT}

Objective To investigate the levels and correlates of physical activity during COVID-19 social distancing in a sample of the UK public.

Methods This paper presents analyses of data from a cross-sectional study. Levels of physical activity during COVID-19 social distancing were self-reported. Participants also reported on sociodemographic and clinical data. The association between several factors and physical activity was studied using regression models.

Results Nine hundred and eleven adults were included (64.0\% were women and $50.4 \%$ of the participants were aged $35-64$ years). $75.0 \%$ of the participants met the physical activity guidelines during social distancing. Meeting these guidelines during social distancing was significantly associated with sex (reference: male; female: $\mathrm{OR}=1.60,95 \% \mathrm{Cl} 1.10$ to 2.33 ), age (reference: $18-34$ years; $\geq 65$ years: $\mathrm{OR}=4.11,95 \% \mathrm{Cl} 2.01$ to 8.92 ), annual household income (reference: $<£ 15000 ; £ 15000-<£ 25$ 000: $0 \mathrm{R}=2.03,95 \% \mathrm{Cl} 1.11$ to 3.76 ; $£ 25000-<£ 40000$ : $\mathrm{OR}=3.16,95 \% \mathrm{Cl} 1.68$ to $6.04 ; £ 40000-<£ 60000$ : $\mathrm{OR}=2.27,95 \% \mathrm{Cl} 1.19$ to 4.34 ; $\geq £ 60000$ : $\mathrm{R}=2.11,95 \%$ $\mathrm{Cl} 1.09$ to 4.09 ), level of physical activity per day when not observing social distancing $(\mathrm{OR}=1.00$ (per $1 \mathrm{~min}$ increase), $95 \% \mathrm{Cl} 1.00$ to 1.01), and any physical symptom experienced during social distancing (reference: no; yes: $\mathrm{OR}=0.31,95 \% \mathrm{Cl} 0.21$ to 0.46 ).

Conclusion During COVID-19, social distancing interventions should focus on increasing physical activity levels among younger adults, men and those with low annual household income. It should be noted in the present sample that women and younger adults are overrepresented.

(c) Author(s) (or their employer(s)) 2020. Re-use permitted under CC BY-NC. No commercial re-use. See rights and permissions. Published by BMJ.

For numbered affiliations see end of article.

Correspondence to

Dr Lee Smith;

lee.smith@anglia.ac.uk

\section{INTRODUCTION}

Physical activity is defined as any bodily movement produced by skeletal muscle that results in energy expenditure. ${ }^{1}$ Regular and sustained participation in physical activity is associated with almost every facet of health across the lifespan ${ }^{2-4}$ and importantly the prevention of all-cause early mortality. ${ }^{5}$ Moreover, acute

\section{What are the new findings}

- In the present sample of UK adults following UK COVID-19 social distancing guidance, a high level of physical activity was observed.

- Meeting physical activity guidelines was observed in women and older adults.

- Interventions should now be developed to support women and older adults in sustaining this level of physical activity post pandemic.

exercise is an immune system adjuvant that improves defence activity and metabolic health. ${ }^{6}$ Global governments have produced recommendations for adequate levels of physical activity. One key message from the WHO guidance is that adults should achieve at least 150 min of moderate physical activity and/or 75 min of vigorous physical activity per week. ${ }^{7}$ However, despite this the proportion of UK adults meeting the physical activity guidelines is low ${ }^{8}$ and declines with age.

Among key determinants of changes in physical activity levels are significant life events. ${ }^{10}$ In March 2020, the WHO declared the COVID-19 outbreak a global pandemic. As of 17 April 2020 (10:00 Central European Time), more than 2160170 cases have been diagnosed globally, with over 68976 fatalities. ${ }^{11}$ On 23 March 2020 the UK government released social distancing guidance to reduce the risk of transmission. This guidance was implemented for an initial 3-week period, with the guidance extended for a further 3 weeks on 16 April 2020. It should also be noted here that prior to the mass guidance, the UK public who were at high risk for serious complications if they contracted COVID19 , lived with someone who was at high risk for serious complications if they contracted 
Table 1 Sample characteristics (overall and by physical activity status)

\begin{tabular}{|c|c|c|c|c|c|c|}
\hline Characteristics & Category & Overall $(n=911)$ & \multicolumn{2}{|c|}{$\begin{array}{l}\text { Sufficient physical activity } \\
\text { per day }\end{array}$} & $\begin{array}{l}\text { Effect } \\
\text { size }^{*}\end{array}$ & $\mathbf{P}$ value \\
\hline \multirow[t]{2}{*}{ Sex } & Male & 36.0 & 37.3 & 35.6 & 0.02 & 0.688 \\
\hline & Female & 64.0 & 62.7 & 64.4 & & \\
\hline \multirow[t]{2}{*}{ Age (years) } & $18-34$ & 31.3 & 40.8 & 28.1 & 0.19 & $<0.001$ \\
\hline & $35-64$ & 50.4 & 53.1 & 49.5 & & \\
\hline \multirow[t]{2}{*}{ Marital status } & Single/separated/divorced/widowed & 44.8 & 55.7 & 41.2 & 0.13 & $<0.001$ \\
\hline & Married/in a domestic partnership & 55.2 & 44.3 & 58.8 & & \\
\hline \multirow[t]{2}{*}{ Employment } & No & 41.3 & 35.5 & 43.2 & 0.07 & 0.050 \\
\hline & Yes & 58.7 & 64.5 & 56.8 & & \\
\hline \multirow[t]{2}{*}{ Annual household income } & $<£ 15000$ & 14.8 & 22.7 & 12.1 & 0.14 & 0.002 \\
\hline & $\geq £ 60000$ & 23.2 & 21.3 & 23.8 & & \\
\hline \multirow[t]{4}{*}{ Region } & England & 77.3 & 81.1 & 76.1 & 0.07 & 0.259 \\
\hline & Northern Ireland & 19.3 & 17.2 & 19.9 & & \\
\hline & Scotland & 2.3 & 0.9 & 2.8 & & \\
\hline & Wales & 1.1 & 0.9 & 1.2 & & \\
\hline \multirow[t]{2}{*}{ Current smoking } & No & 88.2 & 86.3 & 88.8 & 0.03 & 0.377 \\
\hline & Yes & 11.8 & 13.7 & 11.2 & & \\
\hline \multirow[t]{2}{*}{ Current alcohol consumption } & No & 32.7 & 37.2 & 31.2 & 0.06 & 0.114 \\
\hline & Yes & 67.3 & 62.8 & 68.8 & & \\
\hline Number of days of social distancing & Mean (SD) & $9.1(6.9)$ & $8.3(4.2)$ & $9.4(7.6)$ & 0.16 & 0.007 \\
\hline \multicolumn{7}{|c|}{$\begin{array}{l}\text { Participants were asked how much time in minutes they spend on an average day in moderate-to-vigorous physical activity when self-isolating. } \\
\text { The WHO recommendations on physical activity levels per week (ie, at least } 150 \text { min of moderate physical activity and/or } 75 \text { min of vigorous } \\
\text { physical activity in adults aged } \geq 18 \text { years) were further used to distinguish participants with and those without sufficient physical activity per day (ie, } \\
\text { approximately } 21 \text { min of moderate physical activity and/or } 11 \text { min of vigorous physical activity). } \\
\text { Values are percentages unless otherwise stated. } \\
\text { *Effect size was calculated using phi coefficient for categorical variables with two categories, Cramer's } V \text { for categorical variables with more than } \\
\text { two categories, and Cohen's d for continuous variables. } \\
\dagger P \text { values were based on } \chi^{2} \text { tests for categorical variables and on t-tests for continuous variables. }\end{array}$} \\
\hline
\end{tabular}

COVID-19, and the elderly were encouraged to engage in social distancing.

This scenario is certainly a key life event that may have had an impact on population levels of physical activity. Moreover, social distancing guidance may influence physical activity in different ways dependent on age, sex, chronic conditions, socioeconomic status and marital status-all of which have been shown to be associated with physical activity during non-pandemic times. ${ }^{9}{ }^{12-15}$

Therefore, the aim of the present study was to examine the levels of physical activity during the UK COVID-19 social distancing guidance and investigate how such levels vary by sociodemographic, behavioural, clinical and contextual factors.

\section{METHODS}

This paper presents preplanned interim analysis of data from a cross-sectional epidemiological study, administered through an online survey. The study was launched on 17 March 2020, 17 days after the first case of COVID-19 was diagnosed in the UK.

Participants were recruited through social media and through national media outlets. Adults aged 18 years and over, currently residing in the UK and observing social 
distancing due to COVID-19 were eligible to participate. Participants were directed to a data-encrypted website where they indicated their consent to participate after reading an information sheet. Before completing the survey participants were asked if they were currently observing social distancing and were over 18 years of age. If the participant's response was affirmative to both questions, the participant was asked to complete the survey.

\section{Dependent variable}

Participants were asked the following: (1) 'How much time on an average day have you spent in vigorous activity since social distancing?' and (2) 'How much time on an average day have you spent in moderate activity since social distancing?' Responses were reported in hours and minutes. Physical activity when social distancing was included in the analyses as a dichotomous (sufficient physical activity per day: yes or no) and a continuous (number of minutes of moderate-to-vigorous physical activity per day) variable. Following the WHO recommendations on physical activity levels per week, ${ }^{7}$ sufficient physical activity per day was defined as approximately $21 \mathrm{~min}$ of moderate physical activity and/or 11 min of vigorous physical activity per day.

\section{Independent variables}

Demographic data were collected, including sex (male or female), age (in 10-year age bands), marital status (single/ separated/divorced/widowed or married/in a domestic partnership), employment (yes or no) and annual household income (ie, $<£ 15000, £ 15000-<£ 25000$, £25 000-<£40 000, $£ 40000-<£ 60000, \geq £ 60$ 000). Participants were also asked to indicate which of the four main UK countries they lived in. Behavioural factors included current smoking status (yes or no), current alcohol consumption (yes or no) and usual levels of moderate-to-vigorous physical activity per day during non-pandemic times (when not selfisolating). Participants were also asked to report chronic physical conditions. Finally, participants were asked if they had experienced any physical symptoms of COVID-19 during social distancing and the number of days they had been social distancing.

\section{Statistical analyses}

Sample characteristics were compared between participants who met and did not meet the physical activity guidelines using $\chi^{2}$ tests for categorical variables and t-tests for continuous variables. The mean number of minutes of moderate-to-vigorous physical activity per day when social distancing was further compared between male and female participants using t-test, while it was compared between adults aged 18-34 years, those aged 35-64 years and those aged $\geq 65$ years using analysis of variance. Effect sizes were estimated using phi coefficients for categorical variables with two categories, Cramer's V for categorical variables with more than two categories, and Cohen's $d$ for continuous variables. The relationship between defined factors and physical activity during social distancing was studied in

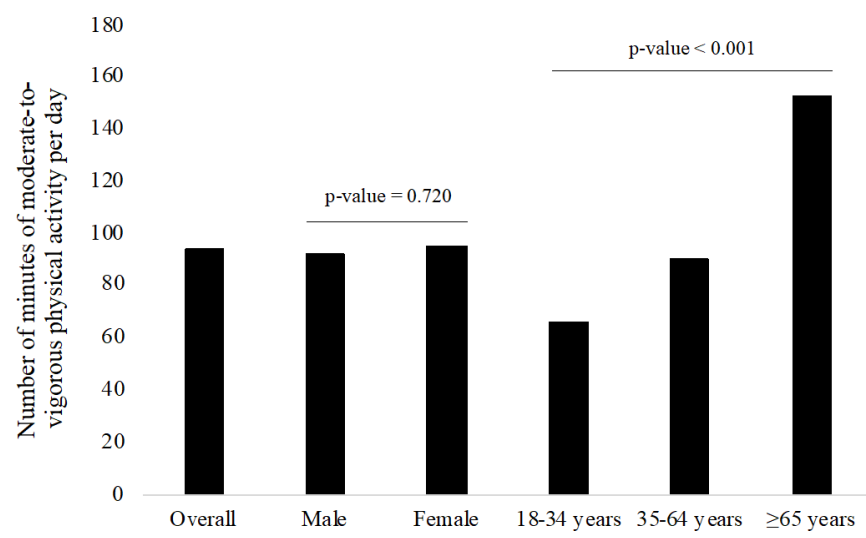

Figure 1 Number of minutes of moderate-to-vigorous physical activity per day during social distancing in the overall sample and in sex and age groups. Participants were asked how much time in minutes they spend on an average day in moderate-to-vigorous physical activity when social distancing. The number of minutes of moderate-to-vigorous physical activity per day was compared between male and female participants using t-test, while it was compared between the three age groups using analysis of variance.

logistic (dichotomous physical activity variable; sufficient physical activity per day: yes or no) and linear regression models (continuous physical activity variable; number of minutes of moderate-to-vigorous physical activity per day). Results from the logistic regression analysis are presented as ORs and 95\% CIs, while beta coefficients with associated 95\% CIs are displayed for the linear regression analysis. The level of statistical significance was set at $p<0.05$. The statistical analysis was performed with R V.3.6.2 (The R Foundation).

\section{RESULTS}

Nine hundred and eleven adults were included in this cross-sectional study $(64.0 \%$ were women and $50.4 \%$ of the participants were aged 35-64 years; table 1). Overall, $75.0 \%$ of participants had sufficient physical activity during social distancing. The mean (SD) number of minutes of moderate-to-vigorous physical activity per day when social distancing was 94.0 (119.1), and significantly increased from 65.8 (77.7) in the age group 18-34 years to 152.9 (146.3) in the age group $\geq 65$ years (figure 1 ). The logistic regression analysis showed that sufficient physical activity during social distancing was significantly associated with sex (reference: male; female: $\mathrm{OR}=1.60,95 \%$ CI 1.10 to 2.33 ), age (reference: $18-34$ years; $\geq 65$ years: $\mathrm{OR}=4.11,95 \% \mathrm{CI}$ 2.01 to 8.92 ), annual household income (reference: $<£ 15$ 000; £15 000-<£25 000: OR=2.03, 95\% CI 1.11 to 3.76 ; £25 $000-<£ 40$ 000: OR $=3.16,95 \%$ CI 1.68 to $6.04 ; £ 40000-<£ 60$ 000: $\mathrm{OR}=2.27,95 \%$ CI 1.19 to 4.34 ; $\geq £ 60$ 000: $\mathrm{OR}=2.11$, 95\% CI 1.09 to 4.09), level of physical activity per day when not social distancing ( $\mathrm{OR}=1.00$ (per $1 \mathrm{~min}$ increase), 95\% CI 1.00 to 1.01 ), and any physical symptom experienced during social distancing (reference: no; yes: $\mathrm{OR}=0.31,95 \%$ CI 0.21 to 0.46 ; table 2). Similar findings were found in linear regression analyses. 
Table 2 Factors associated with physical activity in social distancing adults during the SARS-CoV-2 pandemic in 2020 in the UK

\begin{tabular}{|c|c|c|c|c|c|c|c|}
\hline Characteristics & Category & \multicolumn{3}{|c|}{$\begin{array}{l}\text { Sufficient physical activity per day (dichotomous } \\
\text { variable; logistic regression) }\end{array}$} & \multicolumn{3}{|c|}{$\begin{array}{l}\text { Level of physical activity per day (continuous variable } \\
\text { linear regression) }\end{array}$} \\
\hline Sex & Male & Reference & & & & & \\
\hline \multirow[t]{2}{*}{ Age (years) } & $18-34$ & Reference & & & & & \\
\hline & $35-64$ & 1.44 & 0.94 to 2.20 & 0.091 & 28.09 & 9.54 to 47.03 & 0.003 \\
\hline Marital status & $\begin{array}{l}\text { Married/ } \\
\text { in a domestic partnership }\end{array}$ & 1.38 & 0.92 to 2.06 & 0.119 & 4.48 & -12.28 to 21.37 & 0.601 \\
\hline Employment & No & Reference & & & & & \\
\hline \multirow{2}{*}{ Annual household income } & $£ 40000-<£ 60000$ & 2.27 & 1.19 to 4.34 & 0.013 & 27.40 & -0.74 to 55.29 & 0.055 \\
\hline & $\geq £ 60000$ & 2.11 & 1.09 to 4.09 & 0.026 & 31.24 & 2.71 to 59.59 & 0.031 \\
\hline \multirow[t]{4}{*}{ Region } & England & Reference & & & & & \\
\hline & Northern Ireland & 1.22 & 0.77 to 1.97 & 0.411 & 10.95 & -8.04 to 30.07 & 0.260 \\
\hline & Scotland & 3.42 & 0.84 to 23.35 & 0.128 & -1.37 & -52.46 to 50.02 & 0.958 \\
\hline & Wales & 1.64 & 0.33 to 12.32 & 0.576 & 35.10 & -31.49 to 102.06 & 0.302 \\
\hline \multirow[t]{2}{*}{ Current smoking } & No & Reference & & & & & \\
\hline & Yes & 1.16 & 0.68 to 2.02 & 0.599 & 7.92 & -15.29 to 31.47 & 0.506 \\
\hline Current alcohol consumption & No & Reference & & & & & \\
\hline \multirow{2}{*}{$\begin{array}{l}\text { Any physical symptom } \\
\text { experienced during social } \\
\text { distancing }\end{array}$} & No & Reference & & & & & \\
\hline & Yes & 0.31 & 0.21 to 0.46 & $<0.001$ & -25.53 & -42.46 to -7.99 & 0.004 \\
\hline $\begin{array}{l}\text { Number of days of social } \\
\text { distancing }\end{array}$ & Per 1-day increase & 1.03 & 0.99 to 1.07 & 0.162 & -0.18 & -1.28 to 0.93 & 0.756 \\
\hline
\end{tabular}

Participants were asked how much time in minutes they spend on an average day in moderate-to-vigorous physical activity when self-isolating. The WHO recommendations on physical activity levels per week (ie, at least $150 \mathrm{~min}$ of moderate physical activity and/or $75 \mathrm{~min}$ of vigorous physical activity in adults aged $\geq 18$ years) were further used to distinguish participants with and those without sufficient physical activity per day (ie, approximately $21 \mathrm{~min}$ of moderate physical activity and/or 11 min of vigorous physical activity). Physical activity was also included in the analyses as a continuous variable and corresponded to the number of minutes of moderate-to-vigorous physical activity per day.

The association between defined factors (ie, sex, age, marital status, employment, annual household income, region, current smoking, current alcohol consumption, level of physical activity per day when not self-isolating, number of chronic physical conditions, number of chronic psychiatric conditions, any physical symptom experienced during social distancing and number of days of social distancing) and physical activity was studied using logistic (dichotomous physical activity variable) and linear regression (continuous physical activity variable) models.

All significant associations are reported in bold text.

SARS-CoV-2, severe acute respiratory syndrome coronavirus 2.

\section{DISCUSSION}

The present study found that a total of $75 \%$ of the participants met the physical activity guidelines during UK COVID-19 social distancing. Moreover, women, older adults, those with higher annual household income and those not experiencing physical COVID-19 symptoms were significantly likely to be more physically active.
Previous studies have identified that approximately $58 \%-66 \%$ of the UK adult population meet physical activity guidelines, ${ }^{8}$ whereas the present study found that this level was at $75 \%$ during social distancing. During COVID-19 social distancing the UK public may have experienced an increase in discretionary time and thus may be using this additional discretionary time to be physically active. 
Second, one of the key reasons that one may leave their home grounds during COVID-19 social distancing is to partake in one form of exercise daily for $60 \mathrm{~min}$.

Interestingly higher levels of physical activity were observed in older adults and in women. These findings contradict the literature during non-pandemic times where the younger and men are observed to have higher levels of physical activity. ${ }^{89}$

Findings must be interpreted in light of the study limitations. First, participants were asked to self-report their physical activity level and thus potentially introducing selfreporting bias into the findings. The present survey did not report the domain of physical activity, only overall levels. However, social distancing legislation in the UK meant that individuals were not permitted to go to their place of work and the behaviour recorded would most likely be leisure time physical activity for which physical activity guidelines are based on. Finally, when comparing the present sample with recent UK population estimates, women $(64.0 \%$ vs $50.6 \%)$ and adults aged $18-34$ years (31.3\% vs $19.7 \%$ (20-34 years in the comparison database, strictly speaking)) are over-represented. ${ }^{16}$ Moreover, it is indeed known that online surveys may not yield generalisable, epidemiological samples, but given the nature of restrictions in place on personal contacts there are few options to collect this type of data.

The present findings suggest that during COVID-19, social distancing interventions should focus on increasing physical activity levels among younger adults, men and those with low annual household income. It should be noted in the present sample that women and younger adults are over-represented.

\section{Author affiliations}

${ }^{1}$ The Cambridge Centre for Sport and Exercise Sciences, Anglia Ruskin University, Cambridge, United Kingdom

${ }^{2}$ Faculty of Medicine, University of Versailles Saint-Quentin-en-Yvelines, Montignyle- Bretonneux, France

${ }^{3}$ Faculty of Science and Engineering, Anglia Ruskin University, Cambridge, United Kingdom

${ }^{4}$ Department of Sports Methods and Techniques, Federal University of Santa Maria, Santa Maria, Brazil

${ }^{5}$ Anglia Ruskin University, Cambridge, UK

${ }^{6}$ Department of Social and Preventive Medicine, Centre for Public Health, Medical University Vienna, Vienna, Austria

${ }^{7}$ Geriatric Unit, Department of Internal Medicine and Geriatrics, University of Palermo, Palermo, Italy

${ }^{8}$ School of Sport, Exercise and Rehabilitation, University of Technology, Sydney, New South Wales, Australia

${ }^{9}$ Faculty of Sport Science, University of Murcia, Murcia, Spain

${ }^{10}$ Department of Kinesiology, lowa State University, lowa, Missouri, USA

${ }^{11}$ Department of Special Surgery, University of Jordan, Amman, Jordan

${ }^{12}$ Northern Ireland Public Health Research Network, School of Health Sciences, Ulster University, Ulster, Ireland

${ }^{13}$ HSC R\&D Division, Public Health Agency (Northern Ireland), Belfast, Ireland

${ }^{14}$ Institute of Mental Health Sciences, School of Health Sciences, Ulster University, Newtownabbey, Ireland

Contributors LS, MT, YB, and LB conceived the idea. LS, MT and LJ analysed and interpreted the data. LS drafted the manuscript. All authors critically revised the manuscript and approved the final draft before submission.
Funding The authors have not declared a specific grant for this research from any funding agency in the public, commercial or not-for-profit sectors.

Competing interests None declared.

Patient and public involvement Patients and/or the public were not involved in the design, or conduct, or reporting, or dissemination plans of this research.

Patient consent for publication Obtained.

Ethics approval The study was approved by the Anglia Ruskin University Research Ethics Committee (16 March 2020).

Provenance and peer review Not commissioned; externally peer reviewed.

Open access This is an open access article distributed in accordance with the Creative Commons Attribution Non Commercial (CC BY-NC 4.0) license, which permits others to distribute, remix, adapt, build upon this work non-commercially, and license their derivative works on different terms, provided the original work is properly cited, appropriate credit is given, any changes made indicated, and the use is non-commercial. See: http://creativecommons.org/licenses/by-nc/4.0/.

\section{ORCID iDs}

Lee Smith http://orcid.org/0000-0002-5340-9833

Guillermo F Lopez-Sanchez http://orcid.org/0000-0002-9897-5273

\section{REFERENCES}

1 Caspersen CJ, Powell KE, Christenson GM. Physical activity, exercise, and physical fitness: definitions and distinctions for healthrelated research. Public Health Rep 1985;100:126-31.

2 Cunningham C, O' Sullivan R, Caserotti P, et al. Consequences of physical inactivity in older adults: a systematic review of reviews and meta-analyses. Scand J Med Sci Sports 2020;30:816-27.

3 Warburton DER, Bredin SSD. Health benefits of physical activity: a systematic review of current systematic reviews. Curr Opin Cardiol 2017;32:541-56.

4 Schuch FB, Vancampfort D, Firth J, et al. Physical activity and incident depression: a meta-analysis of prospective cohort studies. Am J Psychiatry 2018;175:631-48.

5 Mok A, Khaw K-T, Luben R, et al. Physical activity trajectories and mortality: population based cohort study. BMJ 2019;365:I2323.

6 Nieman DC, Wentz LM. The compelling link between physical activity and the body's defense system. J Sport Health Sci 2019;8:201-17.

7 World Health Organisation. Global strategy on diet physical activity and health, 2020. Available: https://www.who.int/dietphysicalactivity/ factsheet_recommendations/en/

8 National Health Service. Household survey shows more men than women meet physical activity guidelines, 2020. Available: https:// digital.nhs.uk/news-and-events/news-archive/2017-news-archive/ household-survey-shows-more-men-than-women-meet-physicalactivity-guidelines

9 Smith L, Gardner B, Fisher A, et al. Patterns and correlates of physical activity behaviour over 10 years in older adults: prospective analyses from the English longitudinal study of ageing. BMJ Open 2015;5:e007423.

10 Allender S, Hutchinson L, Foster C. Life-change events and participation in physical activity: a systematic review. Health Promot Int 2008;23:160-72.

11 Johns Hopkins University \& Meicine. Coronavirus resource centre, 2020. Available: https://coronavirus.jhu.edu/map.html

12 Azevedo MR, Araújo CLP, Reichert FF, et al. Gender differences in leisure-time physical activity. Int J Public Health 2007;52:8-15.

13 Barker J, Byrne S. Physical activity of UK adults with chronic disease: cross-sectional analysis of accelerometer-measured physical activity in 96706 UK Biobank participants. Int J Epidemiol 2019:dyy294.

14 O'Donoghue G, Kennedy A, Puggina A, et al. Socio-economic determinants of physical activity across the life course: $A$ "DEterminants of Dlet and Physical ACtivity" (DEDIPAC) umbrella literature review. PLoS One 2018;13:e0190737.

15 Pettee KK, Brach JS, Kriska AM, et al. Influence of marital status on physical activity levels among older adults. Med Sci Sports Exerc 2006;38:541-6.

16 Office for National Statistics. Estimates of the population for the UK, England and Wales, Scotland and Northern Ireland, 2020. Available: https://www.ons.gov.uk/peoplepopulationandcommunity/populati onandmigration/populationestimates/datasets/populationestimatesf orukenglandandwalesscotlandandnorthernireland [Accessed 20 Jun 2020]. 